\title{
Strategi Pemerintah Kabupaten Wonogiri Dalam Mengembangkan Sentra Agroindustri Brem Putih
}

\author{
Mohd. Harisudin, Arip Wijianto, dan Widiyanto \\ Fakultas Pertanian UNS, JI. Ir. Sutami No: 36A Ska \\ Email: harisfpuns@gmail.com
}

\begin{abstract}
Government Wonogiri Strategy for Center of Agro-industry in Developing White Brem. This study aims to analyze condition of white brem agroindustrial center in Wonogiri, Identifying internal and external environmental conditions, Determining alternative strategies and priorities determining the most appropriate strategy applied Wonogiri Government in developing agro-industry white brem centers. This study is a descriptive analytical study using primary and secondary data. Primary data to explain the white brem conditions agroindustry, strategic factors and alternative strategies and determination of the strategy through surveys, observation and focus group discussion. Secondary data in the form of monographs and the potential economic data in Wonogiri regency. Tools Analysis used is the SWOT matrix and the matrix QSP. The study concluded that the centers of agroindustrial white brem in Wonogiri is the average revenue_in May 2011 amounted to Rp 17,634,375, -; cost needed is Rp 16,103,678, - and the revenue of Rp 1,530,697 , -. Strength strategic factors are ease of exchanging information, ease of making sales of products, experience and skills sought a long labor. Strategic factors are drawbacks: The employers are less innovative, less promotional efforts, pieces of white brem uninteresting, unattractive packaging, the center has not been managed well, the strategic factor market opportunities is a high demand, the development of service suppliers of raw materials, the presence of community agencies (bakul), alignments of government policies, developments in food processing technology, development of information technology. Strategic factor is the threat of price fluctuations of raw materials; competitors' similar product innovation, the presence of product substitution, government policies that are less integrated, bright sun /weather. Priority strategies are recommended so that the development of agro-industry centers in the white brem Wonogiri can run effectively is to Improve togetherness among employers to boost innovation in order to increase profits.
\end{abstract}

Keywords: Center of Agro-Industry, white brem, Strategy, QSPM

ABSTRAK: Strategi Pemerintah Kabupaten Wonogiri dalam Mengembangkan Sentra Agroindustri Brem Putih. Penelitian ini bertujuan Menganalisis keragaan sentra agroindustri brem putih di Kabupaten Wonogiri, Mengidentifikasi kondisi lingkungan internal dan eksternal, Menentukan alternatif strategi dan Menentukan prioritas strategi yang paling tepat diterapkan Pemerintah Kabupaten Wonogiri dalam mengembangkan sentra agroindustri brem putih. Penelitian ini merupakan penelitian deskriptif analitik dengan menggunakan data primer dan skunder. Data primer untuk menjelaskan keragaan agroindustri brem putih, faktor strategis dan alternative strategi dan penetapan strategi melalui survey, observasi dan focus group discussion. Data sekunder berupa data monografi dan potensi perekonomian Kabupaten Wonogiri. Alat analisis yang digunakan adalah matriks SWOT dan Matriks QSP. Hasil penelitian menyimpulkan bahwa Keragaan sentra agroindustri brem putih di Kabupaten Wonogiri adalah rata-rata penerimaan setiap pengusaha brem putih pada bulan mei 2011 sebesar Rp 17.634.375,-; biaya yang dibutulkan sebesar Rp 16.103.678,- dan pendapatannya sebesar Rp 1.530.697,-- Faktor-faktor strategis Kekuatan adalah Mudahnya melakukan pertukaran informasi, Mudahnya melakukan penjualan produk, Pengalaman berusaha yang lama dan Keterampilan tenaga kerja. Faktor Strategis kelemahan adalah: Para pengusaha kurang inovatif, upaya promosi kurang, kepingan brem putih tidak menarik, kemasan kurang menarik, sentra belum dikelola dengan baik, Faktor strategis peluang adalah permintaan pasar 
yang tinggi, berkembangnya layanan pemasok bahan baku, terdapatnya komunitas agen/bakul, keberpihakan kebijakan pemerintah, perkembangan teknologi pengolahan pangan, perkembangan teknologi informasi. Faktor strategis ancaman adalah fluktuasi harga bahan baku, inovasi produk pesaing sejenis, hadirnya produk substitusi, kebijakan pemerintah yang kurang terintegrasi, cerahnya sinar matahari/cuaca. Prioritas strategi yang direkomendasikan agar pengembangan sentra agroindustri brem putih di Kabupaten Wonogiri dapat berjalan efektif adalah Memperbaiki kebersamaan diantara pengusaha untuk meningkatkan inovasi guna meningkatkan keuntungan.

Kata Kunci : Sentra Agroindustri, brem putih, Strategi, QSPM

\section{PENDAHULUAN}

\section{Latar belakang}

Pasal 4 ayat 1 dari UU No 33 tahun 2004 tentang perimbangan keuangan antara Pemerintah Pusat dan Pemerintahan Daerah menyebutkan Penyelenggaraan urusan Pemerintahan Daerah dalam rangka pelaksanaan Desentralisasi didanai APBD. Mengacu dengan bunyi ayat diatas, maka Pemerintah Daerah diberi kewenangan untuk menaikkan pendapatannya dengan memaksimalkan potensi daerah. Diberlakukannya - undang-undang tersebut memberikan kewenangan penuh kepada Pemerintah Daerah untuk menggali setiap potensi yang dimiliki guna meningkatkan Pendapatan Asli Daerah (PAD). Menurut Wasito (2006), sebagai perwujudan kewenangan dan tanggung jawab tersebut pemerintah Kabupaten Wonogiri mencanangkan empat pilar pembangunan yang berbasis pada pengembangan industri/ agroindustri, pengembangan perdagangan, pengembangan penanaman modal dan pengembangan koperasi, usaha kecil dan menengah.

Mengacu empat pilar tersebut, pilar agroindustri merupakan pilar yang memiliki arti strategis karena memiliki derivat dari aspek pemberdayaan masyarakat. Menurut Harisudin (dalam Kusnandar, 2010), manfaat lain dari mengembangkan agroindustri adalah sebagai rekayasa sosial dalam menyejahterakan petani dengan perubahan mindset berusaha. Hal ini dimungkinkan karena agroindustri juga berfungsi sebagai pencipta nilai strategis bagi kehidupan suatu bangsa agraris. Diantara agroindustri yang sudah ada sejak lama di Kabupaten Wonogiri adalah agroindustri pengolahan makanan olahan yang disebut dengan nama brem putih.

Mengacu definisi yang dikembangkan oleh Badan Pusat Statistik yang dielaborasi oleh Departemen Perindustrian dan Perdagangan (2002), maka agroindustri brem putih di Kabupaten Wonogiri termasuk dalam kategori agroindustri skala rumah tangga. Agroindustri rumah tangga adalah agroindustri yang jumlah tenaga kerjanya berjumlah antara 1-4 orang. Agroindustri brem putih di Kabupaten Wonogiri secara geografis mengelompok dalam satu kawasan produksi yang terdiri dari kumpulan unit usaha yang menghasilkan barang sejenis. Menurut Azhary (1986), agroindustri yang mengelompok secara geografis dinamakan sentra. Beberapa kelebihan sentra agroindustri brem putih di Kabupaten Wonogiri diantaranya adalah agroindustri brem putih telah mampu menghasilkan jumlah output yang besar sehingga mampu memenuhi permintaan pasar lokal maupun luar daerah (Gusnanto, 2010). Kerjasama 
antar unit usaha dalam sentra agroindustri ini akan memberikan kesempatan tumbuhnya ruang belajar secara kolektif untuk meningkatkan kualitas produk dan pindah ke segmen pasar yang lebih menguntungkan. Jaringan bisnis diantara perusahaan, penyedia jasa layanan usaha (misal institusi pelatihan, sentra teknologi, dan lain-lain) dan perumus kebijakan lokal, dapat mendukung pembentukan suatu visi pengembangan lokal bersama dan memperkuat tindakan kolektif untuk meningkatkan daya saing usaha agroindustri brem putih. Dengan demikian, menurut Azhary (1986) sentra agroindustri dapat menjadi alat yang baik untuk mengatasi hambatan akibat ukuran usaha agroindustri brem putih dan berhasil mengatasi persaingan dalam suatu lingkungan pasar yang semakin kompetitif. Disisi lain, sebagai konsekuensi dari sentra agroindustri brem putih masih sebagai satuan industri rumah tangga- yang berskala kecil, maka sentra ini memiliki beberapa kelemahan yaitu lemahnya modal, sumber daya manusia yang rendah dan keterbatasan teknologi. Selain itu, sentra industri identik sangat bergantung pada peran pedagang perantara atau pedagang pengumpul. Hal ini menunjukkan bahwa sentra industri juga lemah dalam aspek pemasaran.

Perhatian Pemerintah Kabupaten Wonogiri dalam pengembangan sektor informal sentra agroindustri brem putih ternyata hanya bersifat perangsang ataupun stimulan saja yaitu hanya berupa pemberian bantuan alat produksi, yang diberikan baru sekali pada tahun 1985 (Wasito, 2006). Dengan demikian dapat disimpulkan bahwa potensi yang dimiliki sentra agroindustri brem putih di Kabupaten
Wonogiri untuk tumbuh dan berkembang terhambat oleh adanya berbagai keterbatasan dan kelemahan yang dimiliki. Karena itulah, diperlukan satu strategi yang tepat untuk mengembangkan sentra agroindustri brem putih Kabupaten Wonogiri.

\section{Tujuan penelitian}

Tujuan yang ingin dicapai dari penelitian ini adalah:

1. Menganalisis keragaan sentra agroindustri brem putih di Kabupaten Wonogiri

2. Mengidentifikasi kondisi lingkungan internal dan eksternal yang dapat menjadi kekuatan dan kelemahan serta peluang dan ancaman bagi sentra agroindustri brem putih di Kabupaten Wonogiri.

3. Menentukan alternatif strategi dalam pengembangan sentra agroindustri brem putih di Kabupaten Wonogiri.

4. Menentukan prioritas strategi yang paling tepat diterapkan Pemerintah Kabupaten Wonogiri dalam mengembangkan sentra agroindustri brem putih.

\section{METODE PENELITIAN}

Metode yang digunakan dalam penelitian ini adalah metode deskriptif analitis yaitu kombinasi dari metode deskriptif dan metode analitis. Metode analitis bertujuan menguji kebenaran hipotesis dan metode deskriptif bertujuan memperoleh deskripsi yang terpercaya dan berguna (Soeratno dan Arsyad, 1995). Lokasi penelitian ditentukan secara purposive berdasarkan pertimbangan-pertimbangan tertentu sesuai dengan tujuan penelitian (Singarimbun dan Effendi, 1995). Lokasi penelitian yaitu di Desa Bumiharjo dan Desa Gebang, 
Kecamatan Nguntoronadi Kabupaten Wonogiri.

Responden dalam analisis usaha pada penelitian ini adalah keseluruhan pengusaha agroindustri brem putih (sensus) yang masih aktif berproduksi. Berdasarkan data dari Dinas Perindustrian, Perdagangan, Koperasi dan UKM Kabupaten Wonogiri, terdapat dua puluh empat pengusaha agroindustri brem putih di Kabupaten Wonogiri yang kesemuanya terdapat di Desa Gebang dan Desa Bumiharjo.

Responden penentuan faktorfaktor kunci strategis diperoleh dengan melakukan wawancara mendalam (indepth interview) kepada pengusaha agroindustri brem putih melalui penentuan key informan. Adapun teknik penelusurannya menggunakan teknik snowball sampling. Responden

Tabel 1. Pendapatan Rata-Rata Pengusaha Brem Putih pada Sentra Agroindustri Brem putih di Kabupaten Wonogiri bulan Mei 2011

\begin{tabular}{clc}
\hline \hline No & Uraian & per Pengusaha agroindustri brem putih per Mei \\
& $2011(\mathrm{Rp})$ \\
\hline 1. & Penerimaan & 17.634 .375 \\
2. & Biaya & 16.103 .678 \\
3. & Pendapatan & 1.530 .697 \\
\hline \hline
\end{tabular}

Sumber : Analisis Data Primer

Besarnya penerimaan masingmasing pengusaha brem putih bervariasi bergantung pada jumlah produk yang dihasilkan. Jumlah penerimaan pada Tabel 1 merupakan rata-rata penerimaan pengusaha brem putih yang diperoleh dengan cara membagi total penerimaan sentra agroindustri brem putih pada bulan Mei 2011 dengan jumlah pengusaha brem putih yang terdapat dalam sentra agroindustri tersebut. Pada bulan Mei 2011 rata-rata penerimaan yang diperoleh setiap pengusaha brem putih sebesar Rp. 17.634.375,00 dan penentuan bobot dan Nilai Daya Tarik pada matriks QSP dilakukan secara purposive yaitu pejabat yang akan menerapkan strategi pengembangan sentra agroindustri brem putih di Kabupaten Wonogiri. Jenis data terdiri dari data primer dan data skunder, sedangkan teknik pengumpulan datanya dilakukan dengan observasi, wawancara, dan pencatatan. Data yang diperoleh dalam penelitian ini diolah dengan beberapa metode analisis yaitu: Analisis biaya, analisis penerimaan, analisis pendapatan, matriks SWOT dan Matriks QSP (David, 2009).

\section{HASIL DAN PEMBAHASAN}

\section{Keragaan Sentra Agroindustri Brem putih di Kabupaten Wonogiri}


riil yaitu tenaga kerja dalam dan beberapa biaya yang secara riil tidak dikeluarkan oleh pengusaha brem putih di Kabupaten Wonogiri.

Identifikasi Faktor Kekuatan, Kelemahan, Peluang dan Ancaman
Berdasarkan hasil analisis faktor internal dan eksternal maka dapat diidentifikasi kekuatan, kelemahan, peluang dan ancaman yang berpengaruh terhadap pengembangan sentra agroindustri brem putih di Kabupaten Wonogiri. Faktor-faktor kunci strategis tersebut adalah :

Tabel 2. Daftar faktor-faktor kunci strategis pengembangan sentra agroindustri brem putih di Kabupaten Wonogiri

\begin{tabular}{|c|c|c|}
\hline Faktor Internal & Kekuatan & Kelemahan \\
\hline $\begin{array}{l}\text { Sumber Daya } \\
\text { Manusia }\end{array}$ & $\begin{array}{l}\text { - Mudahnya Melakukan } \\
\text { Pertukaran Informasi }\end{array}$ & $\begin{array}{l}\text { - Para pengusaha kurang } \\
\text { inovatif }\end{array}$ \\
\hline Pemasaran & $\begin{array}{l}\text { - Mudahnya melakukan } \\
\text { penjualan produk }\end{array}$ & $\begin{array}{l}\text { - Upaya melakukan promosi } \\
\text { kurang }\end{array}$ \\
\hline $\begin{array}{l}\text { Produksi } \\
\text { /Operasional }\end{array}$ & $\begin{array}{l}\text { - Pengalaman berusaha yang } \\
\text { lama } \\
\text { - Keterampilan Tenaga kerja }\end{array}$ & $\begin{array}{l}\text { - Kepingan brem putih tidak } \\
\text { menarik } \\
\text { - Kemasan kurang menarik }\end{array}$ \\
\hline $\begin{array}{l}\text { Teamwork } \\
\text { pengusaha }\end{array}$ & & $\begin{array}{l}\text { - Sentra belum dikelola } \\
\text { dengan baik }\end{array}$ \\
\hline Faktor Eksternal & Peluang & Ancaman \\
\hline Perekonomian & $\begin{array}{l}\text { - Permintaan pasar yang tinggi } \\
\text { - Berkembangnya layanan } \\
\text { pemasok bahan baku }\end{array}$ & - Fluktuasi harga bahan baku \\
\hline Persaingan & $\begin{array}{l}\text { - Terdapat komunitas agen } \\
\text { pemasaran/bakul }\end{array}$ & $\begin{array}{l}\text { - Inovasi produk pesaing } \\
\text { sejenis } \\
\text { - Hadirnya Produk Substitusi }\end{array}$ \\
\hline Pemerintah & $\begin{array}{l}\text { - Keberpihakan Kebijakan } \\
\text { Pemerintah }\end{array}$ & $\begin{array}{l}\text { - Kebijakan Pemerintah } \\
\text { yang kurang terintegrasi }\end{array}$ \\
\hline Kondisi alam & & $\begin{array}{l}\text { - Cerah tidaknya Sinar } \\
\text { Matahari/Cuaca }\end{array}$ \\
\hline Teknologi & $\begin{array}{l}\text { - Perkembangan teknologi } \\
\text { pengolahan pangan } \\
\text { - Perkembangan teknologi } \\
\text { informasi }\end{array}$ & \\
\hline
\end{tabular}

Sumber : Analisis Hasil Penelitian

\section{Alternatif Strategi}

Alaternatif strategi pengembangan sentra agroindustri brem putih di Kabupaten Wonogiri dirumuskan menggunakan analisis Matriks SWOT. Dengan menggunakan matriks SWOT diharapkan diperoleh fleksibilitas alternnatif strategi, sehingga memungkinkan diterapkannya strategi oleh Pemerintah Kabupaten Wonogiri. Beberapa alternatif strategi untuk mengembangkan sentra agroindustri brem putih di Kabupaten Wonogiri adalah : 
a. Strategi S-O

1) Memanfaatkan Pemerintah dan kemajuan teknologi untuk meningkatkan daya saing produk $(\mathrm{S} 1, \mathrm{O} 2, \mathrm{O} 3$, $\mathrm{O} 4, \mathrm{O} 5, \mathrm{O} 6$ )

2) Meningkatkan peran agen (bakul) dalam menaikkan share produsen (S1, S2, S3, O1, O3, O6)

b. Strategi W-O

1) Memberbaiki visi bisnis pengusaha untuk meningkatkan pendapatan (W1, W2, W3, O1, $\mathrm{O} 3, \mathrm{O} 5, \mathrm{O} 6)$

2) Memperbaiki kebersamaan diantara pengusaha untuk meningkatkan inovasi guna meningkatkan keuntungan (W1, W2, W3, W5, O1, O3, O5, O6)

c. Strategi S-T

Membangun kerjasama kelompok guna mengatasi permasalahan proses produksi dan ancaman produk pesaing (S1, S4, T1, T2, T3, T4, T5)

d. Strategi W-T

Membangun kerjasama kelompok dalam upaya memperbaiki kualitas produk brem putih (W1, W2, W3, W4, W5, T2, T3, T4)

\section{Prioritas Strategi}

Setelah dirumuskan beberapa alternatif strategi dengan Matrik SWOT, langkah selanjutnya adalah menentukan priorotas strategi yang akan diterapkan Pemerintah Kabupaten Wonogiri dalam mengembangkan sentra agroindustri brem putih di Kabupaten Wonogiri. Berikut ini adalah Tabel 3 yang menjelaskan hasil perhitungan dengan menggunakan QSPM.

Dari Tabel 3 dapat diketahui nilai total daya tarik untuk masing-masing alternatif strategi. Berdasarkan nilai tersebut dapat disimpulkan bahwa prioritas strategi Pemerintah Kabupaten Wonogiri dalam Mengembangkan Sentra Agroindustri Brem Putih adalah : Memperbaiki kebersamaan diantara pengusaha untuk meningkatkan inovasi guna meningkatan keuntungan (nilai TAS $=6,12$ ). Strategi ini merupakan strategi yang prioritas karena adanya faktor pendukung bagi keberhasilan para pengusaha agroindustri brem nputih dan pengembangan sentra. Pengusaha agroindustri brem putih yang menempati kawasan tertentu (Desa Bumiharjo dan Gebang) atau disebut sentra memiliki keunggulan komparatif dibanding produk pesaing yang diantara pelaku usahanya berjauhan lokasinya (tidak menempati kawasan yang sama). Kelebihan tersebut adalah masyarakat sekitar sudah menerima dengan baik keberadaan sentra agroindustri brem putih, sehingga tidak ada unsur yang dapat menghalangi pada tahap proses produksi. Dengan diterimanya sentra agroindustri brem putih oleh masyarakat sekitar berarti keberadaan sentra agroindustri berm putih dapat difahami justru memberi manfaat bagi masyarakat sekitar. Diantara manfaat utama dari adanya sentra agroindustri brem putih adalah sebagai penyedia lapangan pekerjaan bagi masyarakat sekitar. 
Tabel 3. Quantitative Strategic Planning Matrix (QSPM) Pengembangan Sentra Agroindustri Brem putih di Kabupaten Wonogiri

\begin{tabular}{|c|c|c|c|c|c|c|c|}
\hline \multirow{3}{*}{ FAKTOR-FAKTOR STRATEGIS } & \multirow{3}{*}{ Bobot } & \multicolumn{6}{|c|}{ alternatif strategi } \\
\hline & & \multicolumn{2}{|c|}{$1 *$} & \multicolumn{2}{|c|}{$2 *$} & \multicolumn{2}{|c|}{$3 *$} \\
\hline & & AS & TAS & AS & TAS & AS & TAS \\
\hline \multicolumn{8}{|l|}{ Faktor Kunci Internal } \\
\hline $\begin{array}{l}\text { 1. Mudahnya Melakukan Pertukaran } \\
\text { Informasi }\end{array}$ & 0,1 & 2 & 0,2 & 3 & 0,3 & 4 & 0,4 \\
\hline 2. Mudahnya melakukan penjualan produk & 0,07 & 1 & 0,07 & 3 & 0,21 & 4 & 0,28 \\
\hline 3. Pengalaman berusaha yang lama & 0,08 & 2 & 0,16 & 4 & 0,32 & 3 & 0,24 \\
\hline 4. Keterampilan Tenaga kerja & 0,07 & 2 & 0,14 & 4 & 0,28 & 3 & 0,21 \\
\hline 1. Para pengusaha kurang inovatif & 0,15 & 2 & 0,3 & 4 & 0,6 & 3 & 0,45 \\
\hline 2. Upaya promosi kurang & 0,16 & 4 & 0,64 & 3 & 0,48 & 2 & 0,32 \\
\hline 3. Kepingan brem putih tidak menarik & 0,15 & 3 & 0,45 & 4 & 0,6 & 2 & 0,3 \\
\hline 4. Kemasan kurang menarik & 0,15 & 3 & 0,45 & 4 & 0,6 & 2 & 0,3 \\
\hline 5. Sentra belum dikelola dengan baik & 0,07 & 2 & 0,14 & 3 & 0,21 & 4 & 0,28 \\
\hline Total & 1,00 & & 2,55 & & 3,6 & & 2,78 \\
\hline \multicolumn{8}{|l|}{ Faktor Kunci Eksternal } \\
\hline 1. Permintaan pasar yang tinggi & 0,15 & 2 & 0,3 & 3 & 0,45 & 4 & 0,6 \\
\hline $\begin{array}{l}\text { 2. Berkembangnya layanan pemasok } \\
\text { bahan baku }\end{array}$ & 0,12 & 3 & 0,36 & 2 & 0,24 & 4 & 0,48 \\
\hline $\begin{array}{l}\text { 3. Terdapat komunitas agen } \\
\text { pemasaran/bakul }\end{array}$ & 0,08 & 4 & 0,32 & 3 & 0,24 & 2 & 0,16 \\
\hline 4. Keberpihakan Kebijakan Pemerintah & 0,08 & 4 & 0,32 & 2 & 0,16 & 3 & 0,24 \\
\hline $\begin{array}{l}\text { 5. Perkembangan teknologi pengolahan } \\
\text { pangan }\end{array}$ & 0,06 & 4 & 0,24 & 2 & 0,12 & 3 & 0,18 \\
\hline 6. Perkembangan teknologi informasi & 0,08 & 4 & 0,32 & 3 & 0,24 & 2 & 0,16 \\
\hline 7. Fluktuasi harga bahan baku & 0,09 & 4 & 0,36 & 2 & 0,18 & 3 & 0,27 \\
\hline 8. Inovasi produk pesaing sejenis & 0,07 & 2 & 0,14 & 4 & 0,28 & 3 & 0,21 \\
\hline 9. Hadirnya Produk Substitusi & 0,07 & 2 & 0,14 & 3 & 0,21 & 4 & 0,28 \\
\hline $\begin{array}{l}10 \text { Kebijakan Pemerintah yang kurang } \\
\text { terintegrasi }\end{array}$ & & & & & & & \\
\hline 11 Cerah tidaknya Sinar Matahari/cuaca & 0,1 & 4 & 0,4 & 2 & 0,2 & 3 & 0,3 \\
\hline Total & 1,00 & & 3,2 & & 2,52 & & 3,28 \\
\hline Total Nilai Daya Tarik & & & 5,75 & & 6,12 & & 6,06 \\
\hline
\end{tabular}

\section{Sumber : Analisis hasil penelitian}

Keterangan :

1* Memanfaatkan Kebijakan Pemerintah dan Kemajuan Teknologi untuk Meningkatkan daya tawar produk $(5,75)$

2* Memperbaiki kebersamaan diantara pengusaha untuk meningkatkan inovasi guna meningkatan keuntungan $(6,12)$

3* Membangun kerjasama kelompok dalam upaya memperbaiki kualitas produk brem putih $(6,06)$ 
Dengan tidak adanya ancaman dari luar, maka perkembangan sentra agroindustri brem putih sangat ditentukan oleh faktor internal diantara pengusaha dalam memaksimalkan segala potensinya. Selain faktor geografis, potensi berkembangnya masing-masing pengusaha brem putih pada sentra agroindustri brem putih di Kabupaten Wonogiri didorong oleh situasi/keadaan dimana diantara pengusaha brem putih tidak merasa bersaing karena memang masingmasing pengusaha sudah memiliki pasar sendiri-sendiri. Dengan demikian, diantara pengusaha brem putih dapat memfokuskan pada sinergitas dari keunggulan-keunggulan yang dimiliki setiap pengusaha brem putih melalui berbagi pengetahuan (knowledge sharing) hal-hal yang dirasa didalam proses produksinya hingga pemasarannya memiliki kelebihan (sebagai derivat dari adanya inovasi) dibanding sesama pengusaha brem putih di sentra Bumiharjo dan Gebang.

Selain itu, kebersamaan yang dibentuk dapat dijadikan sebagai sarana dalam usaha memperbaki daya kreativitas/inovasi diantara pengusaha brem putih. Terminologi inovasi saat ini telah menjadi isu strategis utama sebagai penyebab keberhasilan dalam persaingan bisnis. Untuk itu, kebersamaan yang diharapkan dapat dijadikan sebagai media dalam melakukan berbagai macam strategi fungsional yang fokus kepada pemenuhan kebutuhan konsumen. Dengan demikian, kebersamaan yang terjadi difokuskan pada upaya-upaya meningkatkan keuntungan.

\section{KESIMPULAN}

Berdasarkan hasil penelitian Strategi Pemerintah Dalam Mengembangkan Sentra Agroindustri Brem Putih Di Kabupaten Wonogiri dapat diambil kesimpulan sebagai berikut :

1. Keragaan sentra agroindustri brem putih di Kabupaten Wonogiri adalah rata-rata penerimaan setiap pengusaha brem putih pada bulan mei 2011 sebesar Rp 17.634.375,- ; biaya yang dibutuhkan sebesar $\mathrm{Rp}$ 16.103.678,- dan pendapatannya sebesar Rp 1.530.697,-

2. Faktor-faktor strategis dalam pengembangan sentra agroindustri brem putih di Kabupaten Wonogiri adalah:

a. Kekuatan : Mudahnya melakukan pertukaran informasi, Mudahnya melakukan penjualan produk, Pengalaman berusaha yang lama dan Keterampilan tenaga kerja

b. Kelemahan: Para pengusaha kurang inovatif, upaya promosi kurang, kepingan brem putih tidak menarik, kemasan kurang menarik, sentra belum dikelola dengan baik

c. Peluang : permintaan pasar yang tinggi, berkembangnya layanan pemasok bahan baku, terdapatnya komunitas agen/bakul, keberpihakan kebijakan pemerintah, perkembangan teknologi pengolahan pangan, perkembangan teknologi informasi

d. Ancaman : fluktuasi harga bahan baku, inovasi produk pesaing sejenis, hadirnya produk substitusi, kebijakan pemerintah 
yang kurang terintegrasi, cerahnya sinar matahari/cuaca

3. Alternatif strategi

yang direkomendasikan adalah sebagai berikut :

a. Memanfaatkan kebijakan Pemerintah dan kemajuan teknologi untuk meningkatkan daya saing produk

b. Meningkatkan peran agen (bakul) dalam menaikkan share produsen

c. Memberbaiki visi bisnis pengusaha untuk meningkatkan pendapatan

d. Memperbaiki kebersamaan diantara pengusaha untuk meningkatkan inovasi guna meningkatkan keuntungan

e. Membangun kerjasama kelompok

2. guna mengatasi permasalahan proses produksi dan ancaman produk pesaing

f. Membangun kerjasama kelompok dalam upaya memperbaiki kualitas produk brem putih

\section{DAFTAR PUSTAKA}

Azhary, I. 1986. Industri Kecil: Sebuah Tinjauan dan Perbandingan. LP3ES. Jakarta.

David, F R. 2009. Manajemen Strategi Konsep-Konsep. Terjemahan. Penerbit Salemba Empat buku 1 edisi 12. Jakarta.

Gusnanto, A. 2011. Strategi Pengembangan Sentra Industri Brem Di Kecamatan Nguntoronadi Kabupaten Wonogiri. Skripsi pada Program Studi Agribisnis Fak. Pertanian UNS. Tidak dipublikasikan
4. Prioritas Strategi yang diterapkan agar pengembangan sentra agroindustri brem putih di Kabupaten Wonogiri dapat berjalan baik adalah Memperbaiki kebersamaan diantara pengusaha untuk meningkatkan inovasi guna meningkatkan keuntungan

\section{SARAN}

Untuk menunjang keberhasilan dari implementasi strategi yang direkomendasikan, maka beberapa pihak harus mendukung terfasilitasinya forum bersama tersebut. Adapun fihakfihak yang diharapkan dapat mendukung bagi terbentuknya forum tersebut adalah :

1. Pemerintah

2. Pengusaha brem putih harus menjaga idealisme untuk saling berbagi agar forum dapat berfungsi sebagaimana yang diharapkan, sehingga peningkatan kesejahteraan pengusaha brem putih di Kabupaten Wonogiri dapat dirasakan.

Kusnandar, Mardikanto, T., Wibowo, A. 2010. Manajemen Agroindustri. Sebelas Maret University Press. Surakarta.

Singarimbun, M dan Effendi, S. 1995. Metode Penelitian Survai. LP3ES. Jakarta.

Soeratno dan Lincoln Arsyad. 1995. Metodologi Penelitian Untuk Ekonomi dan Bisnis. YKPN. Yogyakarta.

Wasito, G. 2006. Strategi Pengembangan Industri Brem dalam Pemberdayaan Ekonomi Masyarakat di Desa Gebang Kecamatan Nguntoronadi Kabupaten Wonogiri. UNS Press. Surakarta. 